\title{
25 Research Square

\section{Changes in forest composition and associated biophysical climate feedbacks across boreal North America}

\section{Richard Massey}

Northern Arizona University

\section{Brendan Rogers}

https://orcid.org/0000-0001-6711-8466

\section{Logan Berner}

Northern Arizona University https://orcid.org/0000-0001-8947-0479

Sol Cooperdock

Woodwell Climate Research Center https://orcid.org/0000-0001-9056-7008

\section{Michelle Mack}

Northern Arizona University

\section{Xanthe Walker}

Northern Arizona University

\section{Scott Goetz ( $\nabla$ scott.goetz@nau.edu )}

Northern Arizona University https://orcid.org/0000-0002-6326-4308

\section{Article}

Keywords: albedo, climate change, fire disturbance, radiative forcing, tree cover

Posted Date: January 7th, 2022

DOl: https://doi.org/10.21203/rs.3.rs-1209150/v1

License: (c) (i) This work is licensed under a Creative Commons Attribution 4.0 International License. Read Full License 


\section{Abstract}

Deciduous tree cover is expected to increase in North American boreal forests with climate warming and wildfire occurrence. This shift in composition can generate biophysical cooling effects via increased land surface albedo. Here we use newly derived maps of continuous tree canopy and fractional deciduous cover to assess change over recent decades. We find on average a small net decrease in deciduous fraction cover from 2000 to 2015 across boreal North America, and from 1992 to 2015 across Canada, despite extensive fire disturbance that locally increased deciduous vegetation. We further find a nearneutral net biophysical change in radiative forcing across the domain due to relatively small net changes in albedo. Thus, while there have been widespread changes in forest composition over the past several decades across the domain, the net changes in composition and associated post-fire radiative forcing have not yet induced systematic negative feedbacks to climate warming.

\section{Main Text}

Boreal forest composition in North America (NA) is heavily influenced by wildfires ${ }^{1,2}$. In addition to selfreplacement, severe stand-replacing wildfires often kill needleleaf evergreen trees and drive a shift to deciduous trees in early to mid-succession ${ }^{1-4}$. This is particularly the case when fires burn deeply into organic soils, exposing mineral seedbeds, which in turn promote the recruitment of deciduous trees ${ }^{3,4}$ that can dominate for decades to centuries ${ }^{5-10}$. Climate warming has intensified fire regimes in boreal NA over recent decades, including increased fire frequency, severity and area burned ${ }^{11-13}$. This trend is expected to continue in coming decades ${ }^{8-11}$ and potentially shift NA boreal forests towards more deciduous composition ${ }^{5,6,8,9,14-16}$. Despite advances in understanding trajectories of fire and climate impacts on boreal forests, we lack a continental-scale understanding of changes in deciduous-evergreen composition associated with fires across the NA boreal biome. Past efforts have described local or regional fire-induced shifts in composition, but these efforts were based on field measurements alone ${ }^{6,9}$, ${ }^{16}$, moderately coarse $(500 \mathrm{~m})$ spatial resolution satellite imagery ${ }^{4}$, or categorical classifications of cover types rather than continuous (fractional) per-pixel cover estimates ${ }^{17}$. Lack of comprehensive maps of forest composition change that represent continuous spatial gradients at fine resolution (e.g., $30 \mathrm{~m}$ ) have limited our understanding of the extent, magnitudes and implications of changes in composition associated with changing climate and fire regimes.

Energy budgets of boreal deciduous and evergreen stands differ substantially ${ }^{18}$, and therefore have different impacts on regional and global climate ${ }^{4,19,20}$. The higher surface reflectance and seasonally open canopies of deciduous trees lead to higher albedo than evergreen trees. Albedo often declines as boreal NA forest stands mature and transition to more evergreen cover ${ }^{20,21}$. Although albedo is higher year-round in deciduous stands, the radiative effect is most pronounced in spring due to a combination of little-to-no foliage, the presence of underlying snow, and relatively high insolation. These factors increase outgoing shortwave radiation in early- to mid-successional post-fire stands dominated by deciduous trees, leading to local cooling ${ }^{20,22}$. Because approximately one third of Earth's boreal forest is in $\mathrm{NA}^{23}$ and 
about half of Eurasian boreal forests are deciduous (whether dominated by conifer or broadleaf species), post-fire composition shifts in the NA boreal biome represent one of the largest potential regional energy budget feedbacks to the global climate system ${ }^{19-22}$.

Here we assess changes in deciduous cover over the past two decades across the NA boreal forest based on Landsat satellite observations coupled with an extensive field sample plot network. Moreover, we quantify the magnitude of albedo climate forcings associated with the observed composition changes. As part of this assessment, we developed novel maps of sub-pixel fractional deciduous cover at $30 \mathrm{~m}$ resolution across the entire NA boreal biome as well as coincident maps of tree canopy cover. We used these spatially detailed, multi-temporal maps to assess the influence of forest compositional changes on albedo-driven radiative forcing, both inside and outside of burn perimeters for fires that occurred between 1950 and 2018. We find fires exerted a strong influence on forest composition that persisted for decades, but there was coincident succession of deciduous to evergreen cover, thus relatively small net biomescale change in composition and albedo-driven radiative forcing when aggregated across the domain. Consequently, there have not yet been widespread systematic negative biophysical feedbacks to recent climate warming across boreal North America, despite highly dynamic composition changes locally and regionally.

\section{Results}

\section{Continental-scale fractional deciduous cover}

Earth-observing satellites such as those from the Landsat series ${ }^{24}$ provide global observational data useful for analyzing vegetation dynamics at fine spatial scale and relatively high temporal resolution ${ }^{25}$. We used Landsat satellite data combined with in-situ forest inventory samples from multiple site networks ( $n=27,494$ plots) to develop continental-scale deciduous fractional cover and tree canopy cover maps for the NA boreal forest at multiple time-integrated epochs: 2000, 2005, 2010, and 2015. For the Canadian portion of the domain, which has greater Landsat image coverage, we were able to extent our mapping back to 1992. We used extensive forest inventory data that represents a robust sample of forest species and canopy conditions across broad bioclimatic gradients spanning the NA boreal domain (Fig. 1 and Supplementary Table 1). We determined deciduous fractional cover for each forest inventory plot based on the ratio of basal area of the deciduous trees compared to all trees in the plot. We then used random forest regression models ${ }^{26}$, trained with multi-seasonal Landsat spectral bands and indices, to predict the per-pixel deciduous fractional cover and its uncertainty from plot locations to the entire NA boreal domain. We also developed models to map tree canopy cover for the same epochs. These canopy cover maps represent the fractional areal coverage of tree canopy within each $30 \mathrm{~m}$ Landsat pixel. For subsequent analysis, we considered pixels with tree canopy cover fraction (proportion) greater than 0.25 $(25 \%)$ as tree-dominated based on visual assessment of high-resolution satellite imagery at 110 locations (Supplementary Fig. 1). The combination of per-pixel deciduous fractional cover and tree canopy cover maps provide a comprehensive view of changing gradients of forest composition across the NA boreal domain over multiple time-integrated epochs. 


\section{Deciduous forest fraction cover change}

We assessed changes in forest composition across the boreal forest in NA from 2000 to 2015 and Canada from 1992 to 2015 using the deciduous fractional cover and tree canopy cover layers (Fig. 2). It was not possible to assesses pre-2000 changes in Alaska due to insufficient availability of Landsat imagery. We found the average per-pixel deciduous fraction in the NA boreal domain decreased from 0.33 in 2000 to 0.31 in 2015. Deciduous fraction increased across 171.4 million hectares (Mha; $40 \%$ ) and decreased across 246.9 Mha (58\%) of the 427.6 Mha boreal forest domain (Table 1). Similarly, the average per-pixel deciduous fraction across the Canadian boreal forest decreased from 0.26 in 1992 to 0.24 in 2015 (Table 2). Our results from the 1992 - 2015 (Canada only) and 2000 - 2015 (boreal NA) time periods collectively indicate that, on average, the relative dominance of deciduous trees in the NA boreal forest slightly decreased during the past two to three decades. These findings contrast with past reported increases in the extent of deciduous forest during recent decades across a smaller portion of the NA boreal forest domain based on land cover type classifications ${ }^{17}$.

There were large regional differences in forest compositional change from 2000 to 2015. Average perpixel deciduous fraction decreased nearly twice as much in Alaska $(-0.058)$ than Western $(-0.019)$ or Eastern Canada (-0.023) (Table 3). Examining changes in deciduous fraction across ecoregions ${ }^{27}$, we find the Taiga Shield West was the only ecoregion with an increase in average per-pixel deciduous fraction $(+0.009)$ whereas the largest average per-pixel decreases in deciduous fraction occurred in the Taiga Cordillera (-0.057) and Boreal Cordillera (-0.055) ecoregions (Table 3).

To assess the role of fires in driving compositional change, we examined changes in deciduous fraction inside burned area perimeters of varying ages (Fig. 3). We obtained burned area perimeters from Alaskan and Canadian forest fire agencies ${ }^{27,28}$ and focused on the period from 1950 onward because of potential uncertainties in pre-1950 burned area perimeters. For all fires that occurred after 1950, 59.4 Mha showed increases in deciduous fractional cover and 65.8 Mha showed decreases in deciduous cover during 2000 - 2015. Over the same period, tree canopy cover increased in 51.7 Mha and decreased in 54.3 Mha within fire perimeters (Fig. 3). Fires increased per-pixel boreal forest deciduous fraction by an average of 0.09 , but this was highly dependent on when the fire occurred (Table 1 ; Fig. 3 ).

We then considered three different time periods of fire history: (i) recent fires (1998 - 2018), (ii) intermediate aged fires (1978 - 1998), and (iii) older fires (1950 - 1978). The majority (75\%) of the area with post-fire deciduous fraction increases occurred within burn perimeters of recent to intermediate ages, primarily due to changes from pre-fire evergreen conifers to post-fire early-successional deciduous trees and shrubs. During mid-succession (intermediate aged fires), roughly equal increases and decreases in deciduous fraction were accompanied by an overall increase in tree canopy cover (Fig. 3a,b). Older fires tended to show a continued decline in deciduous fraction as evergreen conifers established dominance (Fig. 3a,b). Overall, our results suggest that "relay floristics" has been widespread after fire ${ }^{20}$, with deciduous fraction initially increasing after fire but then progressively declining as evergreen conifers establish dominance. 


\section{Effect of composition changes on seasonal albedo and radiative forcing}

Forest composition played a major role in changing stand albedo-induced radiative flux. Cooling effects associated with deciduous trees tend to be relatively small in summer but more prominent in spring and fall due to increased snow exposure under deciduous canopies ${ }^{20}$. We determined median seasonal albedo using daily "blue-sky" albedo derived from the MODIS satellites ${ }^{28}$ and then trained random forest models to predict seasonal albedo based on deciduous fraction and tree canopy as predictors. We used the differences between predicted 2000 and 2015 seasonal albedo composite layers to derive seasonal shortwave radiative forcing for spring, summer, and fall. We did not include winter albedo in this study because winter forcings are smaller compared to other seasons at these latitudes and, crucially, the quality of albedo data from remote sensing tends to be unreliable due to short daylengths in the winter months. We note, however, that fire-induced changes in winter albedo and radiative forcing tend to be in the same direction as changes in spring, summer, and fall ${ }^{20}$.

We assessed how changes in deciduous fraction and tree canopy cover between epochs impacted the seasonal albedo and associated radiative forcing. Specifically, we used radiative forcing kernels for albedo $^{28}$ from the Community Atmosphere Model 5 (CAM5) ${ }^{29}$ in the Community Earth System Model (CESM) to calculate seasonal forcing by multiplying differences in albedo values by mean spatiallydownscaled albedo radiative kernels. In addition to domain-wide albedo forcing for tree-dominated pixels, we also assessed forest fire-induced composition alterations using burned area perimeters. Our random forest models explained significant variability in surface albedo with cross-validated $R^{2}$ values of 0.36 . 0.44 , and 0.29 for spring, summer, and fall seasons, respectively with $p<0.05$ for all three seasons. Spring and fall season models had higher explanatory power from tree canopy cover, whereas deciduous fraction explained most of the variability in summer (Supplementary Fig. 2), which is consistent with the phenomenon of underlying snow dominating the albedo signal in non-summer months and tree species composition dominating the signal in summer months ${ }^{21}$.

Across boreal NA, changes in deciduous fraction and tree cover canopy from 2000 to 2015 generated a small net biophysical warming of $0.004 \mathrm{~W} \mathrm{~m}^{-2}$ in spring, $0.004 \mathrm{~W} \mathrm{~m}^{-2}$ in summer, and $0.001 \mathrm{~W} \mathrm{~m}^{-2}$ in fall (average of $0.003 \mathrm{~W} \mathrm{~m}^{-2}$ across non-winter months). These overall changes were the net result of regional heterogeneity in deciduous and evergreen forest changes due to the interplay between fire disturbance history, climate, and other factors (Fig. 4). Although albedo forcings from fires were locally strong within fire perimeters, negative forcings from recent fires and positive forcings from older fires largely cancelled each other out, and thus contributed relatively little to net domain-wide outcomes (Fig. 3f, Fig. 4b-d). Most recent fires $(1998$ - 2018) generated large negative shortwave radiative forcings across all the non-winter seasons due to increases in surface albedo between 2000 and 2015, whereas fire perimeters of intermediate age (1979 - 1998) generated mostly positive seasonal forcings (Fig. 3e). In midsuccessional forests, the overall net change in the deciduous canopy was relatively low but increasing tree cover generated a biophysical warming effect. Similar patterns were observed for older fires (1950 1978), albeit with lower magnitude due to slower changes in forest composition in older stands. The 
overall radiative forcing inside mapped fire perimeters averaged $-0.058 \mathrm{~W} \mathrm{~m}^{-2}$ for spring, $-0.012 \mathrm{~W} \mathrm{~m}^{-2}$ for summer, and $-0.036 \mathrm{~W} \mathrm{~m}^{-2}$ for fall, leading to a relatively small cooling effect across non-winter months (Fig. 3f).

\section{Discussion}

\section{Implications for forest - fire - climate feedbacks in boreal North America}

Our results indicate that despite extensive shifts in forest composition over recent decades, there was little net change in the overall proportion of deciduous and evergreen cover across the North American boreal forest, thus nearly neutral non-winter net radiative forcings over the same time period. Similarly, fires since 1950 contributed relatively little to net changes in forest composition, with increasing deciduous cover and biophysical cooling from recent fires largely being offset by decreasing deciduous cover and biophysical warming from intermediate aged and older fires.

All three major geographic zones showed little change in overall deciduous fraction, which was unexpected given our current understanding of how recent changes in climate and fire regimes affect forest composition. A large body of literature indicates deciduous species are more competitive than evergreen conifers in severely burned areas, a phenomenon exacerbated by the warmer and drier climate Alaska and Canada have experienced over the previous $20-40$ years ${ }^{1,2,7,8}$. Permafrost thaw also leads to more rapid mineralization and increases in plant-available nutrients, which are expected to favor fastgrowing deciduous species over conifers ${ }^{15}$. As a result, several studies have predicted increases in deciduous cover during the 21 st century in Alaska ${ }^{14,15}$ and associated decreases in landscape flammability ${ }^{10,20}$. While such large-scale increases in deciduous trees may still occur, our results suggest such a transition has not yet produced a systematic domain-wide shift.

Within burned areas, our results show slow but consistent increases in evergreen dominance in older fire scars counteract increases in deciduous cover from recent fires. This phenomenon is consistent with increasing evergreen cover outside mapped fire scars, as our analysis only included fire perimeters as old as 1950 and gradual successional changes can occur even 100 years after fires ${ }^{30}$. Decades of fire suppression around an expanding wildland urban interface in Alaska and Canada may have also played a role in increasing evergreen cover ${ }^{31,32}$. Other potential factors may include the impacts of drought and insect outbreaks on deciduous tree species ${ }^{33-35}$, an inability for deciduous trees to regenerate in thick organic soils without severe fires, and the role of jack (Pinus banksiana) and lodgepole (Pinus contorta) pine in post-fire succession throughout much of Canada ${ }^{36-38}$.

Future changes in fire frequency, timing and severity could alter these patterns and successional cycles ${ }^{4}$, 6,9 . For example, with fires in the boreal domain projected to increase with warming climate, the successional pathways of post-fire deciduous species such as Populus tremuloides (quaking aspen) being replaced by evergreen conifers such as Picea mariana (black spruce), Picea glauca (white spruce) and Pinus banksiana (Jack pine) during intermediate and older fire ages may occur less frequently, 
thereby prolonging the persistence of deciduous forest cover. More frequent re-burns also progressively decrease organic soil depth and expose greater areas of mineral soil, and deciduous trees are able to rapidly regenerate vegetatively, thereby increasing the proportion of deciduous trees across the landscape. Post-fire regional cooling is also expected to increase in the future with an intensifying fire regime $^{18}$, although earlier snow melt will likely decrease the magnitude of cooling ${ }^{22}$. This effect is expected to be most pronounced in areas with high evergreen forest cover and closed canopies. The fact that we did not, on balance, observe such changes across the domain during the past 20-30 years highlights the potential for other mechanisms in conifer-deciduous dominance, such as some conifer species (e.g. black spruce) being replaced post-fire by other evergreen conifers (e.g. jack and lodgepole pine) more tolerant of drought conditions on mineral soils.

\section{Methods}

Deciduous fractional layers: We developed deciduous fraction layers using random forest regression models in a supervised-learning approach (Supplementary Fig. 3). We used Landsat satellite data ${ }^{24}$ from Landsat $5 \mathrm{TM}$, Landsat $7 \mathrm{ETM+}$, and Landsat $8 \mathrm{OLI}$ sensors to derive deciduous fractional cover and tree canopy cover layers at 30-meter spatial resolution. While the Landsat datasets are publicly available to download through the United States Geological Survey (USGS), we used Google Earth Engine ${ }^{39}$ (GEE) to pre-process these datasets via GEE python application programming interface (API). We used Landsat 5, 7, and 8 Collection 1 surface reflectance (SR) datasets for years 1987-1997, 1998-2002, 2003-2007, 2008-2012, and 2013-2018 to derive normalized difference vegetation index (NDVI)-based medianvalue image composites for nominal years $1992,2000,2005,2010$, and 2015, respectively. We used NDVI to derive median-value composites for spectral bands which were then used to calculate other indices. These image composites were prepared for early spring, mid-summer, and fall seasons to identify key differences in deciduous and evergreen green-up amplitudes (Supplementary Table 2; Supplementary Fig. 4). In addition to Landsat surface reflectance bands, we added several vegetation indices derived from Landsat bands as additional features for the random forest regression model: 1) normalized difference vegetation index (NDVI), 2) normalized difference wetness index (NDWI), 3) soil-adjusted vegetation index (SAVI), 4) variable atmospherically-resistant index (VARI), and 5) enhanced vegetation index $(\mathrm{EVI})$. With the three seasonal composites and addition of slope, elevation, and aspect as topographical variables from GMTED2010 dataset ${ }^{40}$, the image composite layer-stack consisted of 36 bands or features (Supplementary Fig. 5). The GMTED dataset was used to exclude any discontinuities in the topographical data due to latitude, or other factors.

We obtained ground samples for modeling deciduous fraction from 1) the Cooperative Alaska Forest Inventory $(\mathrm{CAFI})^{41}$, 2) the Bonanza Creek Long Term Ecological Research (BNZ LTER) samples in Alaska $^{42}, 3$ ) repeatedly-measured permanent sample plots $(\mathrm{PSPs})^{43}$ from the Canadian provinces of Yukon, Northwest Territories, British Columbia, Alberta, Saskatchewan, Manitoba, and Ontario, 4) ground sample plots from Northwest Territories ${ }^{44}$, and 5) Canadian National Forest Inventory ${ }^{45}$ plot data for sites across Canada (Fig. 1 and Supplementary Table 1). These ground samples include specie-specific basal 
areas at each site. We converted the specie-specific basal areas to deciduous fraction by taking ratio of deciduous tree basal area to total tree basal area to be used as the response variable in random forest ${ }^{26}$ regression models.

We used the RandomForestRegressormodule in scikit-learn python package as our random forest regression model. We divided the sample locations geographically into zones: 1) east and 2) west (Supplementary Fig. 6) due to differences in spatial density of ground samples, significantly different model outputs, and large variations in importance of input features in the random forest regression models. In addition to geographically distinct random forest models, we trained two temporally distinct random forest models for each zone: 1) a 3-season model, using spring, summer, and fall seasonal composites and 2) a 1-season model, using summer seasonal image composite. The 1-season model used summer season image composite as input and was applied to pixels where all three seasons spring, summer, and fall were not available resulting in gaps in the 3-season model output. To reduce bias in the random forest models due to data imbalance because of the large number of evergreen sample plots, we resampled each zone's sample set by binned under-sampling to create a near uniform distribution of the response variable - deciduous fraction (Supplementary Fig. 7). The random forest models were then parameterized using a multi-dimensional grid-search approach with number of trees (n_estimators), maximum number of features per tree (max_features), minimum number of samples per split node per tree (min_samp_split), and minimum number of samples at each leaf node in a tree (min_samp_leaf) as parameters (Supplementary Table 3). For each combination of the parameters, we parameterized 1,000 5fold cross-validated model runs up to a total of 30 million models to perform a grid search for parameter sets resulting in the highest mean cross-validated r-squared value, low root mean-squared error (RMSE) and low standard deviation in RMSE (Supplementary Table 3). The random forest regression models were then applied to tiled Landsat image composites. Landsat derived seasonal composites bands that are highly correlated (absolute value of correlation coefficient $>0.95$; Supplementary Fig. 8) were not used in random forest models as inputs. We used variable importance plots to assess and validate bands used in the random forest models (Supplementary Fig. 9). We also used one standard deviation of all samples in output leaves across all the decision trees in the random forest regression model as a measure of uncertainty for deciduous fractional cover layers. Additionally, the samples not used in training the model were used to provide an estimate of variance explained by the RF model using adjusted $r^{2}$ value and model performance using root mean squared error (RMSE) value (Supplementary Table 3). Spatial autocorrelation effects in validation samples were reduced by resampling all the validation plot locations via gridding and using a minimum distance threshold of $1 \mathrm{~km}$.

\section{Tree canopy cover layers}

The tree canopy cover layers were developed using a random forest modelling framework similar to deciduous fraction (Supplementary Fig. 3). The training sample were selected in a stratified random manner, with a stratum for each tree canopy cover level and were extracted from the Global tree cover data for $2010^{25}$. We then used the tree canopy cover sample locations to extract band values from the 3season 36 band image layer-stack. Similar to deciduous fraction modelling approach, we used the 
RandomForestRegressor module in scikit-learn python package as our random forest regression model to derive tree canopy cover layers. We also used a 1-season model to fill in the gaps in output of the 3season model. However, we did not divide the study area into different zones for tree canopy cover. We used $30 \%$ of the ground samples that were selected to build the models exclusively for model validation for tree canopy cover layers. The parameterization of the model was performed similar to the deciduous fractional layer approach (Supplementary Table 3). To determine uncertainty in tree canopy cover value we again used one standard deviation of all the samples in output leaves across all the decision trees in the random forest regression model.

Assessing change and albedo-based radiative forcing: We used spring (March - May), summer (June August), and fall (September - October) season image-composites of the blue-sky albedo product for $2000,2005,2010$, and 2015 to assess changes in albedo along with deciduous fraction and tree canopy cover. In each seasonal mean-value composite, we used solar zenith angle $>70$ deg in valid data values. Areas with low post-fire tree cover were included in our analyses because they had higher pre-fire tree cover values. To examine the strength of relationship between albedo, deciduous fractional cover, and tree canopy cover, we modelled albedo for spring (March - May), summer (June - August), and fall (September - October) using albedo data from 2000, 2005, and 2010 in a random forest supervisedlearning approach (Supplementary Fig. 3). We extracted stratified random samples within each 0.1 albedo interval to train the random forest regression model from the blue-sky albedo product seasonal composites. We parameterized the random forest model by optimizing r-squared and RMSE values using a multi-dimensional grid-search approach to determine the best set of random forest regression parameters: $n \_$estimators, max_features, min_samp_split, and min_samp_leaf (Supplementary Table 4). We multiplied the difference in our modeled albedo between the two epochs 2015 and 2000 by the "allsky" CESM-CAM5 albedo kernel ${ }^{28}$ to compute radiative forcing. We extracted mean values of positive and negative change in deciduous fraction, tree canopy cover, blue-sky albedo composites, and radiative forcing to assess changes inside fire perimeters and across the entire domain. We then used fire boundaries obtained from Alaska Large Fire Database ${ }^{46}$ and Canadian National Fire Database ${ }^{47}$ for fires that occurred between 1950 and 2018 to assess change. We used $>500,000$ stratified random samples to assess the validity of deciduous canopy layers by examining the relationships between deciduous fractional cover, tree canopy cover, and uncertainties (Supplementary Fig. 10).

\section{Caveats}

Although our deciduous fractional cover and tree canopy layers capture the variation in tree-based forest composition across the boreal domain (Supplementary Fig. 11), they do not specifically consider the understory component of the boreal forest. In our analysis, we included trees that are above the height of $1.5 \mathrm{~m}$. This excluded understory vegetation component may contribute to the unexplained variance in the deciduous fraction regression model. Another limitation of this analysis is the dependency on multispectral data to extrapolate deciduous fraction and tree canopy cover across the boreal domain. Since we trained the regression model on the spectral reflectance of tree-based deciduous fraction, there may be locations where the spectral reflectance of shrubs and other vegetation types resembles that of the treed 
components. While we used tree canopy cover as a masking layer to only include treed forest in our study, locations with high shrub density may be modelled as having higher tree canopy cover than the threshold, making them difficult to exclude. Further, per-pixel deciduous fraction does not categorically depict vegetation cover. While $30 \mathrm{~m}$ spatial resolution is fine enough to represent homogeneous vegetation, this pixel size may include mixed vegetation types such as deciduous shrubs and evergreen trees. Such mixing can occur for mid to lower tree canopy cover resulting in some pixels having a deciduous fraction value different from forest stands on the ground. Lastly, due to lack of remote sensing data for an entire fire cycle, which is typically of the order of 80-150 years ${ }^{19}$, we analyzed variations in older fire scars across a time-period of 15 years to assess changes in forest composition and forcing in early to midsuccessional post-fire periods. We did not analyze fires in late-successional period in this study due to lack of reliable fire perimeter data from fires that occurred 80-150 years ago. However, our assessment of changes in forest composition and forcing for the entire North American boreal domain provides an indication of variations in such late-successional fire perimeters. We also were not able to integrate albedo and associated radiative forcing estimates for winter months. However, we note the direction of albedo changes and forcing in winter tends to follow that in spring and fall ${ }^{20}$, and, as such, we do not expect this to alter our conclusions. Finally, we were unable to account for potentially earlier snowmelt in spring due to warming during the analysis periods, which would otherwise lead to more biophysical warming ${ }^{21}$.

\section{Software}

We used Python 3.7.5 programming language for all workflows in this analysis. Data extraction from the raster layers was performed using custom packages and codes written in python programming language. All statistical and machine learning analyses were performed using python packages numpy 1.15 .0 , scipy 1.2.0, and scikit-learn 0.23.2.

\section{Data Availability}

The data sets generated by this study will be made publicly available through the Oak Ridge National Laboratory Distributed Active Archive System (ORNL DAAC).

\section{Code Availability}

We developed custom python packages geosoup and geosoupML to process, extract, and manipulate geospatial data on multiple compute platforms and to use random forest and multiple linear regressor to extrapolate deciduous fraction and tree canopy cover from point samples over the entire boreal domain in our workflow and codes. The custom python packages are available at: https://github.com/masseyr/geosoup and https://github.com/masseyr/geosoupML, respectively. We also developed python package eehelper primarily to extract and manipulate geospatial data using GEE. This python package is available at: https://github.com/masseyr/eehelper. The python codes and bash scripts used in our work are available at: https://github.com/GEODE-Lab/DeciduousFraction. 


\section{Declarations}

Competing interests

The authors declare no competing interests.

\section{Author contributions}

R.M., S.J.G and B.M.R. designed the study. R.M., S.J.G and B.M.R. and L.T.B. wrote the manuscript with inputs and edits from all co-authors. S.C., L.T.B., M.C.M. and X.J.W aided in field sample acquisition and data processing. Landsat data processing, machine learning workflows, and analyses were led by R.M. with assistance of L.T.B.

\section{Acknowledgements}

This work was supported by the National Aeronautics and Space Administration (NASA) Arctic Boreal Vulnerability Experiment (ABoVE) grants NNX17AE44G and 80NSSC19M0112, the Department of Defense (DoD) Strategic Environmental Research and Development Program (SERDP) grant RC18-1183, and NASA Carbon Cycle Science Program grant NNX17AE13G. Landsat Surface Reflectance (SR) data were provided by the United States Geological Survey. Computing resources used for this work include the Google Earth Engine cloud computing platform, the NASA ABoVE Science Cloud, and Northern Arizona University's high-performance computing cluster Monsoon.

\section{References}

1. Johnstone JF, Rupp TS, Olson M, Verbyla D. Modeling impacts of fire severity on successional trajectories and future fire behavior in Alaskan boreal forests. Landscape Ecology 2011, 26(4): 487500.

2. Hanes CC, Wang X, Jain P, Parisien M-A, Little JM, Flannigan MD. Fire-regime changes in Canada over the last half century. Canadian Journal of Forest Research 2019, 49(3): 256-269.

3. Barrett K, McGuire AD, Hoy EE, Kasischke E. Potential shifts in dominant forest cover in interior Alaska driven by variations in fire severity. Ecological applications 2011, 21(7): 2380-2396.

4. Beck PSA, Goetz SJ, Mack MC, Alexander HD, Jin Y, Randerson JT, et al. The impacts and implications of an intensifying fire regime on Alaskan boreal forest composition and albedo. Global Change Biology 2011, 17(9): 2853-2866.

5. Soja AJ, Tchebakova NM, French NHF, Flannigan MD, Shugart HH, Stocks BJ, et al. Climate-induced boreal forest change: Predictions versus current observations. Global and Planetary Change 2007, 56(3-4): 274-296. 
6. Alexander HD, Mack MC, Goetz S, Beck PSA, Belshe EF. Implications of increased deciduous cover on stand structure and aboveground carbon pools of Alaskan boreal forests. Ecosphere 2012, 3(5): Article 45.

7. Turetsky MR, Kane ES, Harden JW, Ottmar RD, Manies KL, Hoy E, et al. Recent acceleration of biomass burning and carbon losses in Alaskan forests and peatlands. Nature Geoscience 2010, 4(1): 27-31.

8. Johnstone JF, Hollingsworth TN, Chapin FS, Mack MC. Changes in fire regime break the legacy lock on successional trajectories in Alaskan boreal forest. Global Change Biology 2010, 16(4): 12811295.

9. Mack MC, Walker XJ, Johnstone JF, Alexander HD, Melvin AM, Jean M, et al. Carbon loss from boreal forest wildfires offset by increased dominance of deciduous trees. Science 2021, 372(6539): 280.

10. Veraverbeke S, Rogers BM, Goulden ML, Jandt RR, Miller CE, Wiggins EB, et al. Lightning as a major driver of recent large fire years in North American boreal forests. Nature Climate Change 2017, 7: 529.

11. Flannigan $M$, Stocks $B$, Turetsky $M$, Wotton $M$. Impacts of climate change on fire activity and fire management in the circumboreal forest. Global Change Biology 2009, 15(3): 549-560.

12. Young AM, Higuera PE, Duffy PA, Hu FS. Climatic thresholds shape northern high-latitude fire regimes and imply vulnerability to future climate change. Ecography 2017, 40(5): 606-617.

13. Whitman E, Parisien M-A, Thompson DK, Flannigan MD. Short-interval wildfire and drought overwhelm boreal forest resilience. Scientific Reports 2019, 9(1): 18796.

14. Foster AC, Armstrong AH, Shuman JK, Shugart HH, Rogers BM, Mack MC, et al. Importance of treeand species-level interactions with wildfire, climate, and soils in interior Alaska: Implications for forest change under a warming climate. Ecological Modelling 2019, 409: 108765.

15. Mekonnen ZA, Riley WJ, Randerson JT, Grant RF, Rogers BM. Expansion of high-latitude deciduous forests driven by interactions between climate warming and fire. Nature plants 2019, 5(9): 952-958.

16. Baltzer JL, Day NJ, Walker XJ, Greene D, Mack MC, Alexander HD, et al. Increasing fire and the decline of fire adapted black spruce in the boreal forest. Proceedings of the National Academy of Sciences 2021, 118(45): e2024872118.

17. Wang JA, Sulla-Menashe D, Woodcock CE, Sonnentag O, Keeling RF, Friedl MA. Extensive land cover change across Arctic-Boreal Northwestern North America from disturbance and climate forcing. Global Change Biology 2019, 0(0): 1-16.

18. Amiro B, Orchansky A, Barr A, Black T, Chambers S, Chapin lii F, et al. The effect of post-fire stand age on the boreal forest energy balance. Agricultural and Forest Meteorology 2006, 140(1-4): 41-50.

19. Randerson JT, Liu H, Flanner MG, Chambers SD, Jin Y, Hess PG, et al. The Impact of Boreal Forest Fire on Climate Warming. Science 2006, 314: 3.

20. Rogers B, Randerson J, Bonan G. High-latitude cooling associated with landscape changes from North American boreal forest fires. 2013. 
21. Rogers BM, Soja AJ, Goulden ML, Randerson JT. Influence of tree species on continental differences in boreal fires and climate feedbacks. Nature Geosci 2015, 8(3): 228-234.

22. Potter S, Solvik K, Erb A, Goetz SJ, Johnstone JF, Mack MC, et al. Climate change decreases the cooling effect from postfire albedo in boreal North America. Global change biology 2020, 26(3): 1592-1607.

23. Brandt JP, Flannigan M, Maynard D, Thompson I, Volney W. An introduction to Canada's boreal zone: ecosystem processes, health, sustainability, and environmental issues. Environmental Reviews 2013, 21(4): 207-226.

24. Wulder MA, Loveland TR, Roy DP, Crawford CJ, Masek JG, Woodcock CE, et al. Current status of Landsat program, science, and applications. Remote Sensing of Environment 2019, 225: 127-147.

25. Hansen MC, Potapov PV, Moore R, Hancher M, Turubanova SA, Tyukavina A, et al. High-Resolution Global Maps of 21st-Century Forest Cover Change. Science 2013, 342(6160): 850.

26. Breiman L. Random Forests. Machine Learning 2001, 45: 5-32.

27. Wiken E, Jiménez Nava F, Griffith G. North American Terrestrial Ecoregions-Level III. Commission for Environmental Cooperation: Montreal, Canada, 2011.

28. Pendergrass AG, Conley A, Vitt FM. Surface and top-of-atmosphere radiative feedback kernels for CESM-CAM5. Earth System Science Data 2018, 10(1): 317-324.

29. Hurrell JW, Holland MM, Gent PR, Ghan S, Kay JE, Kushner PJ, et al. The community earth system model: a framework for collaborative research. Bulletin of the American Meteorological Society 2013, 94(9): 1339-1360.

30. Viereck LA. Wildfire in the taiga of Alaska. Quaternary Research 1973, 3(3): 465-495.

31. Calef M, Varvak A, McGuire AD, Chapin III F, Reinhold K. Recent changes in annual area burned in interior Alaska: The impact of fire management. Earth Interactions 2015, 19(5): 1-17.

32. Stocks B, Martell DL. Forest fire management expenditures in Canada: 1970-2013. The Forestry Chronicle 2016, 92(3): 298-306.

33. Hogg E, Brandt J, Michaelian M. Impacts of a regional drought on the productivity, dieback, and biomass of western Canadian aspen forests. Canadian Journal of Forest Research 2008, 38(6): 1373-1384.

34. Boyd MA, Berner LT, Foster AC, Goetz SJ, Rogers BM, Walker XJ, et al. Historic declines in growth portend trembling aspen death during a contemporary leaf miner outbreak in Alaska. Ecosphere 2021, 12(6): e03569.

35. Boyd MA, Berner LT, Doak P, Goetz SJ, Rogers BM, Wagner D, et al. Impacts of climate and insect herbivory on productivity and physiology of trembling aspen (Populus tremuloides) in Alaskan boreal forests. Environmental Research Letters 2019, 14(8): 085010.

36. Johnstone JF, Chapin FS. Non-equilibrium succession dynamics indicate continued northern migration of lodgepole pine. Global Change Biology 2003, 9(10): 1401-1409. 
37. Bouchard M, Pothier $D$, Gauthier S. Fire return intervals and tree species succession in the North Shore region of eastern Quebec. Canadian Journal of Forest Research 2008, 38(6): 1621-1633.

38. Harper K, Bergeron Y, Gauthier S, Drapeau P. Post-fire development of canopy structure and composition in black spruce forests of Abitibi, Québec: a landscape scale study. Silva Fennica 2002, 36(1).

39. Gorelick N, Hancher M, Dixon M, llyushchenko S, Thau D, Moore R. Google Earth Engine: Planetaryscale geospatial analysis for everyone. Remote Sensing of Environment 2017, 202: 18-27.

40. Danielson JJ, Gesch DB. Global multi-resolution terrain elevation data 2010 (GMTED2010). US Department of the Interior, US Geological Survey, 2011.

41. Malone T, Liang J, Packee EC. Cooperative Alaska Forest Inventory. Gen. Tech. Rep. PNW-GTR-785 U.S. Department of Agriculture, Forest Service, Pacific Northwest Research Station: Portland, OR, 2009.

42. Alexander HD, Mack MC. Gap regeneration within mature deciduous forests of Interior Alaska: Implications for future forest change. Forest Ecology and Management 2017, 396: 35-43.

43. Hayden J, Kerley J, Carr D, Kenedi T, Hallarn J. Ontario forest growth and yield program: field manual for establishing and measuring permanent sample plots. Ministry of Natural Resources, Ontario Forest Research Institute., 1995.

44. Marshall KE, Baltzer JL. Decreased competitive interactions drive a reverse species richness latitudinal gradient in subarctic forests. Ecology 2015, 96(2): 461-470.

45. Gillis MD, Omule A, Brierley T. Monitoring Canada's forests: the national forest inventory. The Forestry Chronicle 2005, 81(2): 214-221.

46. Alaska Large Fire Database. Available from Alaska Interagency Coordination Center (AICC) webpage: http://fire.ak.blm.gov/, [Last accessed 5 May 2019]. 2018.

47. Canadian National Fire Database. Available from Natural Resources Canada webpage: http://cwfis.cfs.nrcan.gc.ca/datamart [Last accessed 5 May 2019]. 2018.

\section{Tables}

Table 1: Average changes in forest deciduous fraction and tree covered areas, albedo, and seasonal forcing between 2000 and 2015 for fire perimeters and the boreal domain. Seasonal forcings are means \pm $1 \mathrm{SD}$. 
Fire perimeters

$\begin{array}{lll}1950- & 1978- & 1998- \\ 1978 & 1998 & 2018\end{array}$

All fire

perimeters
Boreal

domain

Increase in deciduous fraction

(10 $0^{6}$ Hectares)

5.93

16.12

22.40

51.66

171.37

Decrease in deciduous fraction

( $10^{6}$ Hectares)

Increase in tree canopy cover

( $10^{6}$ Hectares)

Decrease in tree canopy cover

(10 $0^{6}$ Hectares)

18.88

16.61

10.10

54.34

246.89

Spring warming $\left(\mathrm{W} / \mathrm{m}^{2}\right)$

15.64

26.61

3.00

51.76

181.22

9.17

6.13

29.51

54.25

236.86

$0.181 \pm$

$0.316 \pm$

$0.154 \pm$

0.192

0.131

$0.241 \pm$

0.171

$0.073 \pm$

0.130

Spring cooling $\left(\mathrm{W} / \mathrm{m}^{2}\right)$

$-0.038 \pm$

0.175

$-0.028 \pm$

$-0.47 \pm$

0.184

0.232

$-0.306 \pm$

0.095

0.140

Summer warming $\left(\mathrm{W} / \mathrm{m}^{2}\right)$

$0.035 \pm$
0.011

$0.046 \pm$

$0.028 \pm$

0.02

0.016

$0.039 \pm$

0.020

$-0.065 \pm$

0.197

Summer cooling $\left(\mathrm{W} / \mathrm{m}^{2}\right)$

$-0.029 \pm$

$-0.033 \pm$

$-0.061 \pm$

0.023

0.028

$-0.051 \pm$
0.030

$0.013 \pm$

0.026

Fall warming $\left(\mathrm{W} / \mathrm{m}^{2}\right)$

$0.08 \pm$

0.059

$0.159 \pm$

0.102

$0.077 \pm$

0.072

$0.118 \pm$

0.089

0.017

Fall cooling $\left(\mathrm{W} / \mathrm{m}^{2}\right)$

$-0.057 \pm \quad-0.065 \pm$

0.082

0.087

$-0.209 \pm$

0.109

$-0.153 \pm$

0.112

$-0.009 \pm$ 0.027

Table 2: Areal extent of changes in forest deciduous fraction and tree cover from 1992 to 2015 for fire perimeters and the boreal forest in Canada. Units of area are in Mha $\left(10^{6}\right.$ hectares).

Forest attribute change Fire perimeters

1950 -

1978

Deciduous fraction

increased

Deciduous fraction

decreased

Tree cover increased

Tree cover decreased
4.62

15.23

14.67

5.19

19.95

9.50
All fire

1998 -

2018

15.64

45.10

42.89

44.61

43.38
Canadian boreal forest

$0.034 \pm$ 0.074

$-0.033 \pm$ 0.091 perimeters 
Table 3: Average change in forest deciduous fraction and areal extent of changes from 2000 to 2015 across boreal regions and ecoregions in North America. Deciduous fraction ranges from 0 to 1. Eastern Canada includes Ontario, Quebec, Newfoundland, and Labrador, while Western Canada includes Yukon, Northwest Territories, Nunavut, British Colombia, Alberta, Saskatchewan, and Manitoba.

Domain
Area of increase in deciduous fraction (Mha)
Area of decrease in deciduous fraction (Mha)

\section{deciduous}

fraction

\section{Region}

Eastern

Canada

Western

Canada

Alaska

$-0.058$

70.3

79.4

$-0.023$

$-0.019$

77.0

119.8

20.5

25.0

\section{Ecoregion}

Taiga Plain

$-0.010$

19.2

22.5

Taiga Shield

0.009

9.0

10.1

West

Taiga Shield $\quad-0.005$

16.0

16.9

East

Boreal

Shield East

$-0.033$

31.5

37.0

Boreal

Shield West

$-0.014$

27.7

31.6

Boreal Plain

$-0.014$

15.8

37.5

Taiga

$-0.057$

18.6

21.8

Cordillera

\section{Boreal}

$-0.055$

15.3

26.9

Cordillera

Hudson

$-0.019$

9.4

Plain

\section{Figures}




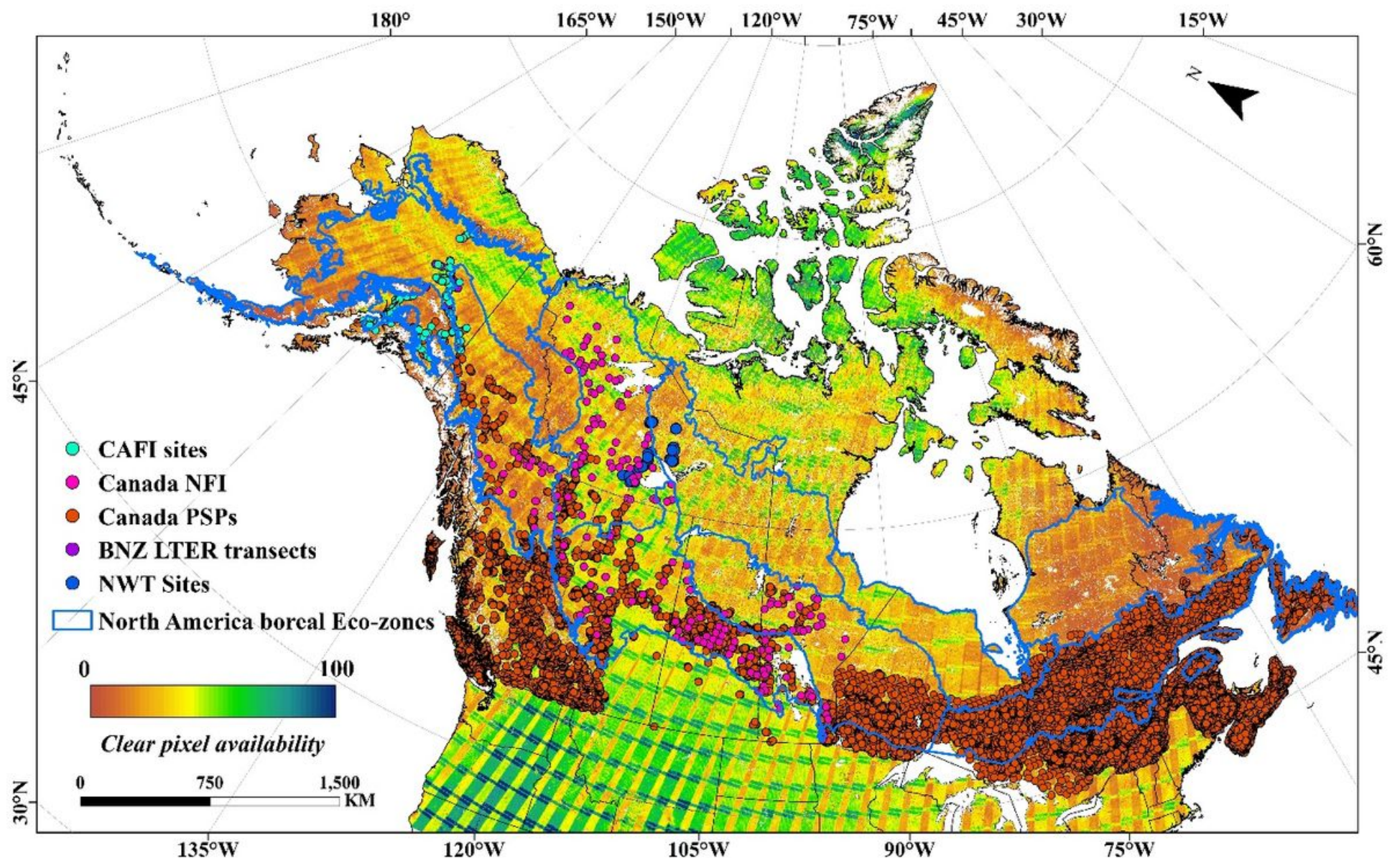

Figure 1

Distribution of forest inventory data used for mapping deciduous fractional cover across boreal North America. Field inventory data were from multiple sources. Study domain is outlined in blue. The background image depicts the availability of clear-sky Landsat measurements from each grid cell for the nominal year 2010 . 

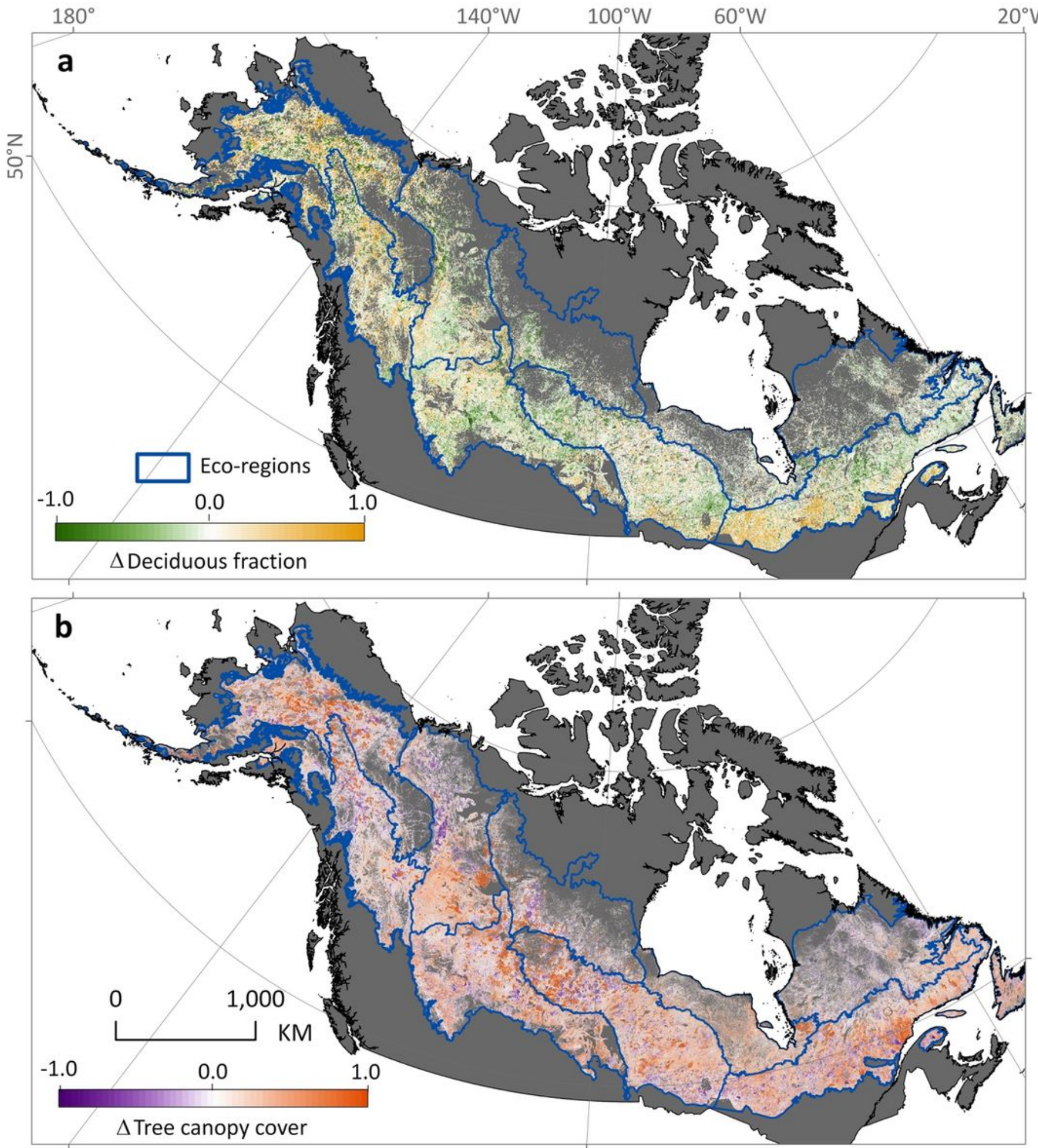

Figure 2

Changes in deciduous fraction and tree canopy from 2000 to 2015. Changes $(\Delta)$ in (a) deciduous fractional cover and (b) tree canopy cover from 2000 to 2015 across the North American boreal domain. 
Change in deciduous fraction, tree canopy cover, albedo, and seasonal forcing between 2000 and 2015 . (a) Average change in per-pixel deciduous fraction and tree canopy cover inside fire perimeters by fire occurrence date. (b) Area with small (under \pm 0.1 ) and large (over \pm 0.1 ) changes in deciduous fraction and tree canopy cover by three fire age classes (i) old (1950 - 1978), (ii) intermediate (1979 - 1998), and (iii) recent $(1999-2018)$. (c) Area with small (under \pm 0.1 ) and large (beyond \pm 0.1 ) changes in deciduous fraction and tree canopy cover within fire perimeters (i) and for the boreal domain (ii). (d) Average change in spring and summer albedo inside fire perimeters. (e) Average radiative forcing by three fire age classes and their first standard deviation values as error bars. (f) Average radiative forcing within the fire perimeters (i) and for the North American boreal domain (ii). Note here $\Delta$ represents change in the represented variable between 2000 and 2015. The grey dashed lines in (a) and (d) indicate the date ranges of Landsat images used in the 2000 and 2015 deciduous fraction and tree canopy cover products. The axes above and below the zero line in (b) indicate non-negative values. Error bands $(\mathbf{a}, \mathbf{d})$ and bars (e,f) represent \pm 1 SD.
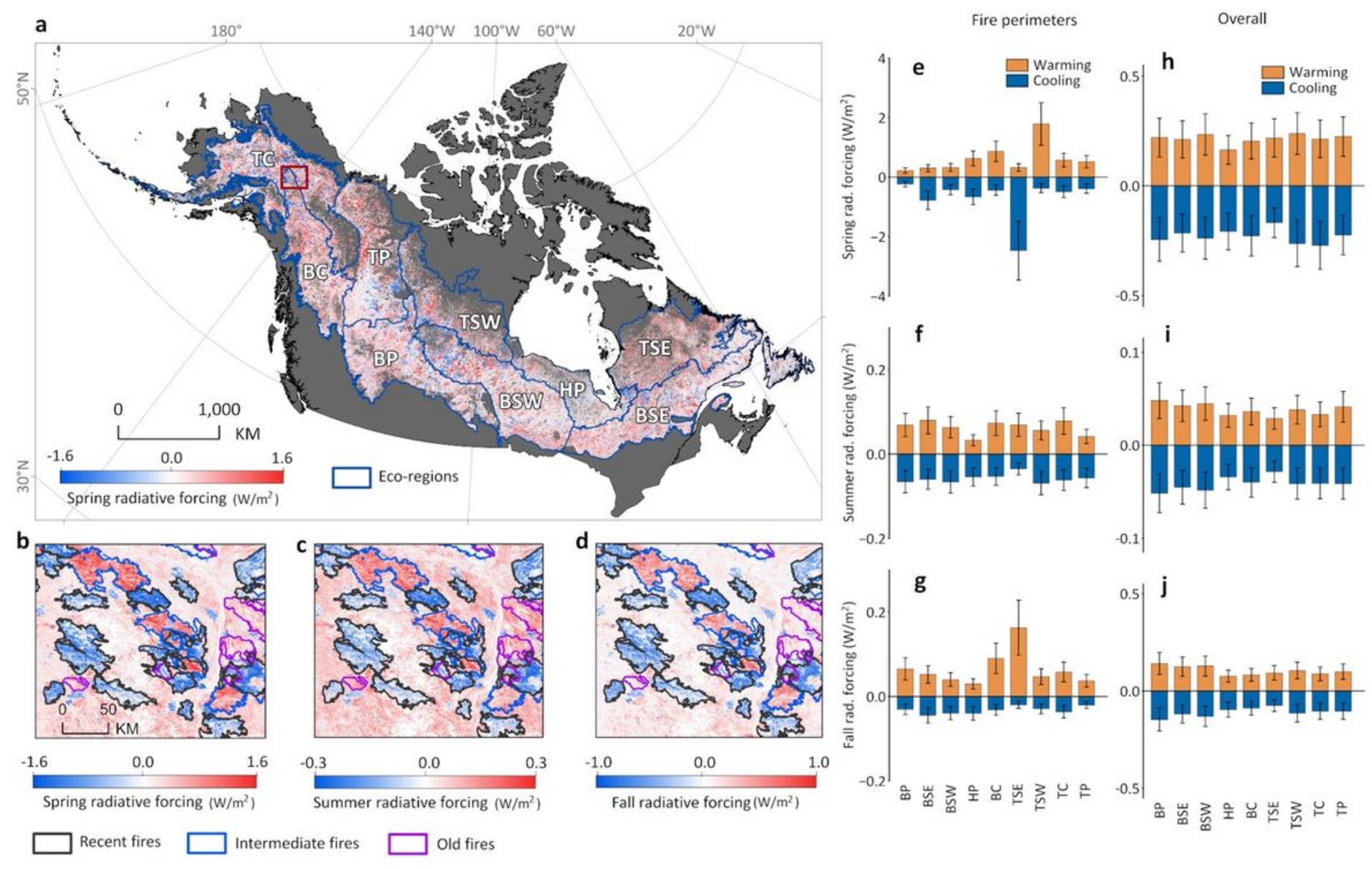

Figure 4

Radiative forcing across boreal domain. Per-pixel spring forcing (a) for boreal domain in North America between 2000 and 2015 with changes in (b) spring , (c) summer, and (d) fall radiative forcing inside recent (1999 - 2018), intermediate (1979 - 1998), and older (1950 - 1978) fire perimeters in a small 
portion of interior Alaska (marked with red boundary in the change map). Average ( $\pm 1 \mathrm{SD}$ ) positive and negative forcing $(\mathbf{e}, \mathbf{f}, \mathbf{g})$ within fire perimeters and $(\mathbf{h}, \mathbf{i}, \mathbf{j})$ overall for each ecoregion in the boreal domain. Ecoregions include the Taiga cordillera (TC), Taiga plain (TP), Boreal plain (BP), Boreal cordillera (BC), Taiga shield west (TSW), Boreal shield west (BSW), Hudson plain (HP), Taiga shield east (TSE), and Boreal shield east (BSE). Note we only included fire perimeters with cumulative areas greater than 10,000 hectares.

\section{Supplementary Files}

This is a list of supplementary files associated with this preprint. Click to download.

- DecidfracsupplementalNCC20211227.docx 